\title{
SOBRE MUDANÇAS E CONTINUIDADES NA GESTÃO URBANA BRASILEIRA
}

\author{
on mutabilities and durabilites in the brazilian urban management
}

\author{
Clóvis Ultramari* \\ Olga Lúcia C. de Freitas Firkowski**
}

\begin{abstract}
Resumo
$\mathrm{O}$ artigo resulta de uma reflexão sobre trabalhos anteriores no âmbito de atividades desenvolvidas junto a administrações municipais e de outras referências acadêmicas sobre a temática. Parte-se do pressuposto de que existe uma complexa e cumulativa agregação de responsabilidades ao gestor urbano brasileiro e, sem ainda poder constatar um presente igualitário e capaz de conciliar interesses ambientais e sociais ao longo do período analisado, reconhecem-se indícios de mudanças positivas naquilo que diz respeito a mudanças há muito desejadas. O enfoque dessas análises é o da gestão urbana voltada ao atendimento básico e tradicional a demandas da sociedade urbana. Para tanto, inicialmente faz-se uma retrospectiva sobre a gestão urbana no Brasil, entre os anos de 1970 e 2010, numa tentativa de síntese de 40 anos de um processo urbano que se intensifica e se complexifica, reconhecendo nele quatro possíveis fases ou momentos que possuem certas especificidades internas. Em seguida, procede-se à descrição de um cenário sobre as práticas urbanas para a próxima década, que poderiam explicar o atual contexto de melhores indicadores, anunciando, antes de uma situação ideal, melhoras significativas se comparadas com um passado pouco distante. Reconhece-se a dificuldade e limitação de tal empreitada, porém esta é realizada com o único intuito de provocar um debate sobre o que se fez e como tal esforço pode apontar para uma nova cidade brasileira.
\end{abstract}

Palavras-chave: Gestão Urbana, Cidades Brasileiras, Planejamento Urbano.

\section{Abstract}

This article results from authors previous investigations and other academic references on this topic, mostly those formulating retrospective analysis on Brazilian urban management. Discussion observes complex and cumulative responsibilities to the Brazilian urban planner and manager. Authors do not identify an equalitarian social reality nor a conciliatory relation between societal and environmental interests; therefore, they make clear there are signals of positive changes in terms of long desired ideas. First part of the article contains a retrospective of the Brazilian urban management recent history, pretentiously formulating a synthesis for the period from the 1970's to the 2010's. Based on selected indicators, second part elaborates a scenario for the next decade. Authors recognize the construction of such scenario risky, but discussion is taken on the sole purpose of provoking future and deeper debates. This scenario is followed by an investigation on the causes for such a better reality. Conclusions are presented, again, in a provocative way, suggesting more debates, but based on a rare optimism: if "brazilianization" once meant urban crisis, it now may also indicate "examples to be replicated".

Key words: Urban management, Brazilian cities, Urban planning.

\section{Resumen}

El artículo resulta de una revisión de estudios previos de los autores y de otras referencias autorales con intereses retrospectivos de la gestión urbana en Brasil. Su constatación principal es la existencia de una compleja y cumulativa agregación de responsabilidades al gestor urbano. Sin poder todavía constatar un mundo presente igualitario y capaz de conciliar intereses ambientales y sociales al longo del tiempo analizado, anuncia indicios de cambios positivos. La primera sección es una retrospectiva sobre la gestión urbana en Brasil, de los años 1970 hasta 2010: un longo proceso urbano que se intensifica y se complejifica. La segunda parte contiene, a partir de indicadores seleccionados, la descripción de un escenario para la próxima década. El ensayo sobre los cuatro posibles períodos de la gestión urbana es seguido por una discusión acerca de las prácticas en el Brasil urbano que podría explicar el actual contexto de mejores indicadores. Si el artículo no puede todavía anunciar una situación ideal, presenta mejoras significativas en comparación con el pasado no mucho distante. Las conclusiones respetan el carácter provocativo y optimista del artículo: si antes "brazilianization" indicaba crisis urbana, ahora puede indicar ejemplos de una replicablidad positiva.

Palabras clave:Gestión urbana, Ciudades brasileñas, Planificación urbana

(*) Bolsista Produtividade do CNPQ. Prof. Dr. do Programa de Pós-Graduação em Gestão Urbana da Pontifícia Universidade Católica do Paraná - Rua Imaculada Conceição 1155, CEP: 81.611-970 - Curitiba (PR) - Brasil, Tel: (+55 41$) 33613459$ ultramari@yahoo.com

(**) Bolsista Produtividade do CNPQ. Prof ${ }^{a}$. Drª . do Programa de Pós Graduação em Geografia da Universidade Federal do Paraná - Centro Politécnico, Cx. Postal 19001, CEP: 81.531-970 - Curitiba (PR) - Brasil, Tel: (+ 55 41) 33613459 - olgafirk@ufpr.br 


\section{INTRODUÇÃO}

Formados num cenário de crise econômica e social, muitos de nossos técnicos e acadêmicos nacionais se habituaram a uma postura de crítica, de receios e de desencanto. São técnicos e acadêmicos que conheceram a chamada década de 1970, ou de enfrentamento com uma nova e pouco entendida sociedade urbana; a década de 1980, ou a década perdida; a década de 1990 com os ensaios de um fracassado neoliberalismo; e ainda a década dos anos 2000 que apresentam um incipiente resultado frente ao enorme esforço de se valorizar o social.

A definição desses momentos se impõe, com nuanças e com sobreposições do melhor e do pior de cada um deles, mas, de modo geral, sempre se revelando com indicadores de uma crise generalizada e marcante. Tal foi a realidade e tal foi a busca por soluções; do ponto de vista da construção de uma verdadeira escola de gestão urbana, o Brasil, ironicamente, constituiu-se em um laboratório rico em fenômenos e profícuo em experiências de enfrentamento. Em termos de fenômeno, vale a lembrança da expressão "brazilianization" que em algum momento tornou-se sinônimo de crise urbana temida nos países centrais e há muito observada nos países mais pobres; em termos de experiência, lembra-se aqui da replicabilidade que ora se observa em relação aos princípios trazidos pelo Estatuto da Cidade (Lei Federal $n^{0} 10.257$, de 2001). As duas citações abaixo explicitam, primeiro, esse temor provocado pela cidade brasileira; segundo, a capacidade técnica e parlamentar nacionais em sugerir soluções.

But the 'dual city' shifted to the 'advanced' world. Conceptually and literally. Common wisdom and analysts both observe that the colonial city has selectively moved to the metropole taking its race and relative poverty with it. "Increasingly, an underclass exists of different ethnic origin from the ruling strata, giving many world cities a 'Third World' aspect," describes contemporary world cities Anthony King (1990: 29). Analysts now write about "third-worlding at home, in NYC" (Koptiuch, 1991), or the "Brazilianization" of Britain (Massey, 1988) which are but some of the conceptualizations of the dualization of the 'advanced' world the most common being the notions of 'advanced marginality' and 'the dual city.' (BODNAR,, 2007, p. 6).

At the level of the nation state, the Brazil City Statute, 2001, is a groundbreaking law that redefined the concept of land ownership, establishing the social value of urban land, and a requirement for democratic participation in urban planning. (UN-HABITAT, 2008, p. 7)

Tais fenômenos urbanos diversos e suas formas de enfrentamento também diversas permitem um esboço de categorização temporal da gestão urbana brasileira. Desse modo, tem-se portanto no Brasil o reconhecimento de momentos que ora respondiam aos sinais de crise e ora optavam por recrudescer indicadores já bastante negativos.

Ressalta-se o receio metodológico em reconhecer tais momentos como períodos, isto porque a periodização deve necessariamente recair sobre um tempo longo, que engloba décadas e suas variáveis intrínsecas, ou como afirma Santos (2002, p. 24) "períodos são pedaços de tempo definidos por características que interagem e asseguram o movimento do todo". Desse modo, o que aqui se ensaia constitui uma simples ferramenta de análise; está explícito desse modo o seu entendimento como momentos de determinação flexível.

Visando a facilitar a compreensão de como a gestão urbana se comportou numa curta retrospectiva, ou seja, como o fenômeno urbano foi tratado pelo estado brasileiro, em suas escalas federal, estaduais e municipais, sugere-se aqui sua síntese em quatro "possíveis" grandes momentos, ainda que guardem particularidades e que algumas realidades se sobreponham temporalmente. Assim, se trata de uma possibilidade de periodização que, contudo, não se apresenta como definitiva, tendo em vista o olhar que se lança sobre os acontecimentos e a priorização de certos elementos constitutivos da realidade. Aqui, a definição de fases ou momentos por meio da cronologia das décadas é uma 
simplificação da realidade observada, havendo, como foi dito, grandes períodos de sobreposição de ideias e fatos, do mesmo modo que há, reconhecem-se, possíveis permanências de características para além dos limites temporais aqui estabelecidos.

Não se trata, portanto, de um esforço de periodização como aqueles encontrados em Leme (1999) e Villaça (1999), que tratam de períodos longos na compreensão do urbanismo brasileiro, neles, os recortes temporais e a metodologia de análise, permitiram a definição de períodos complexos, com início ainda no século XIX, com duração variável entre 10 e 50 anos.

Neste artigo, de modo mais ensaístico que o adotado pelos autores citados, adota-se a visualização da tratativa de nossas cidades em quatro grandes momentos distintos a serem a seguir descritos. Essa tratativa tem o objetivo de contextualizar, numa rápida retrospectiva, os principais instrumentos de uma "possível" política urbana brasileira recente e anunciar mudanças que parecem ocorrer.

Relativamente aos quatro momentos considerados, no recorte temporal que se inicia nos anos 1970, tem-se primeiramente um modelo mais difundido de gestão que se poderia denominar de Ação Administrativa. Neste caso, as prefeituras brasileiras veem seus espaços de trabalho como um mero compromisso de provimento de infraestruturas e serviços urbanos. Desnecessário repetir que essa foi uma responsabilidade não cumprida, já anunciando a construção dos altos déficits em termos dessas mesmas infraestruturas e serviços que ainda hoje se observam. Neste momento, ainda que distantes da consecução total dos objetivos que o caracterizou, ressaltam-se os repasses financeiros do governo federal, a sua instrumentalização pelos governos estaduais e a sempre presente participação de agências internacionais de financiamento, essas capazes de impor um modus operandi urbano não apenas em nível de Brasil mas também em nível global. Tem-se então, uma clara ingerência das agências internacionais de investimento na gestão das cidades brasileiras e que prosseguiria para além dos anos 1970. Tal processo considera não apenas o repasse de recursos segundo regras definidas por um ideário internacional mas implica também no repasse de práticas que encontraram um campo fértil em nossas cidades.

As ideias sempre tiveram tratamento privilegiado por parte do BM. Elas têm sido seu principal produto. Kapur (2006, p. 159) argumenta que, se o BM fosse apenas um agente financeiro, seu staff poderia se limitar a um décimo do quadro atual. Os empréstimos para projetos seriam o combustível para movimentar ou para colocar as ideias em prática (Kapur, 2006). A principal função de cada empréstimo do BM é servir como um "cavalo de Tróia ideológico" (Kapur; Lewis; Webb, 1997, p. 14). Isto é, os empréstimos do BM se constituem em um pacote contendo recursos financeiros e ideias, sendo que, desde a década de 1980, o acesso aos recursos financeiros está condicionado à adoção de suas ideias pelo país-cliente. (RIBEIRO FILHO, 2006, p 122).

Mais precisamente no caso brasileiro, a década de 1970 foi marcada pela disponibilidade de recursos, via governo federal, a ser repassado aos municípios, os quais, todavia, se caracterizavam por grandes limitações técnicas do corpo funcional, operacional, instrumental (restrita estrutura legal) e gerencial. Mais que isso, tal disponibilidade contábil não era suficiente para enfrentar os grandes fluxos demográficos de um campo que ora dava sinais de estagnação econômica ora de modernização, mas sempre implicando na redução demográfica e na migração campo-cidade. Esse cenário de internalização de recursos restringia a atuação das prefeituras a uma simples posição operativa, com destaque para as difundidas e conhecidas obras chamadas estruturais: saneamento, sistema viário, transporte, escolas e estruturas básicas de saúde pública. Desta fase, alguns municípios souberam internalizar mais que outros os recursos disponíveis, valendo-se de algumas situações prioritárias como as de capitais de estado, de municípios localizados nas regiões de fronteira, de municípios com interesse turístico, mas sobretudo daqueles que contavam com uma forte representação parlamentar que pudesse defender seus interesses no executivo da União. Avaliar os resultados desse momento é uma tarefa de difícil consecução e, recorrentemente, sintetizada como de enormes insucessos ou de resultados limitados a áreas formais e de maior renda das cidades. Os 
recursos que estavam disponíveis, as prioridades que foram definidas e a opção gerencial assumida nesta década (por muitos denominada de tecnicista, a qual parecia não reconhecer as especificidades sociais de cada cidade, nem tampouco um eventual interesse de a sociedade participar no que mais lhe interessava e importava), se sujeitas a grandes críticas, deviam ainda atuar em ambiente adverso ao planejamento. Tais ferramentas, práticas e recursos tiveram, de fato, de responder aos efeitos de uma crise econômica com altas taxas de desemprego e, para aquilo que interessava mais especificamente ao gestor urbano, um forte fluxo migratório campo-cidade constituindo demandas difíceis de serem atendidas seja pelos seus aspectos qualitativos (população incapacitada de participar de um mercado de trabalho urbano) ou quantitativos (altas taxas de crescimento ainda não experimentadas em nossa história urbana).

Tal situação de grandes demandas já anunciava, de fato, o momento seguinte, o da década de 1980, onde começa a ficar claro o esgotamento da capacidade governamental em responder às demandas urbanas que se apresentavam. Essa situação provoca a adoção de novas posturas frente ao problema urbano; com isso, o então modelo de Ação Administrativa que havia caracterizado os anos 1970 cede lugar a iniciativas de caráter emergencial, passando-se, então, a se ter uma cidade gerida por interesses de desenvolvimento: a Ação Administrativa da década anterior passa a ser pois um modelo muito mais próximo, desejadamente, daquele de uma Gestão Urbana. Agora, obrigatoriamente, ampliam-se as competências do então administrador urbano para o do gestor urbano. Tal fato ocorreria não apenas pela reduzida capacidade de inversão por parte do Estado, mas sobretudo pelo incremento das complexidades observadas no espaço urbano, anunciando um novo modelo de construção e apropriação de nossas cidades.

Iniciar-se-ia assim uma segunda fase da gestão urbana brasileira mais recente. Se, no momento anterior, ainda se estava atrelado a uma forte dicotomia rural-urbano, onde o crescimento urbano era visto com temor e ainda persistiam crenças num possível retorno ao campo ou mesmo num congelamento da população das já metrópoles brasileiras, os anos 1980 começam, pois, a enxergar as cidades como um fenômeno inevitável que perseguia sua consolidação e não o contrário.

São dessa época as constatações de que intervenções físicas - um dos principais compromissos do então administrador urbano dos anos 1970 -, a despeito de necessárias, não foram suficientes para uma verdadeira transformação das cidades. Da agora simples atenção ao sistema viário, transporte, educação e saúde, tão caras ao administrador urbano, tem-se também outras questões, adicionais e não excludentes, a enfrentar. Essas dizem respeito à pauperização da população, ao desemprego, à violência e ao acirramento na posse do solo urbano, dentre outros. É do final dessa década, por exemplo, o início da discussão sobre o que se chamaria de reforma urbana, lembrando uma disputa fundiária já conhecida no campo.

Essas questões seriam agora, pretensamente, atribuições daqueles que trabalhavam a cidade, indicando pois um caminho de complexidades crescentes que cada vez mais caracterizava a discussão e implementação de políticas públicas de modo geral e não apenas aquelas pensadas para o espaço urbano.

No final da década de 70, percebeu-se a efetivação do propósito do planejamento centralizado e da execução desconcentrada .... Deram origem ao conceito do "fazejador" que, em síntese, significava que nada mais havia a pensar e sim a executar ... no período de 1976/84, a escassez de recursos ... e o direcionamento dos investimentos para setores específicos, principalmente àqueles que atendessem às demandas sociais com vistas a desmobilizar focos de tensão revelados nos movimentos sociais, deram início a um processo de ruptura na estrutura do planejamento e atuação do estado ... (COMEC, 1991, p.12).

O administrador urbano deixa, pois, de ser um prestador de serviços, o qual, de fato, não cumpriu sua função de modo universal e igualitário no espaço urbano, passando a ser um agente que busca o chamado desenvolvimento da cidade. Aos técnicos em arquitetura, engenharia, administração e 
direito - o primeiro mais afeito ao planejamento, o segundo à obra, o terceiro à administração propriamente dita e o último à legislação - são agora agregados uma multitude de formações, mas sobretudo com forte preocupação com o social e o econômico. Assim, a complexidade urbana anunciada na teoria das cidades parece agora ser assimilada pela gestão de fato desses espaços, constituindo, sem dúvida, um avanço no sentido da atuação sobre o território administrado. Se, da década de 1970, ainda era possível observar as intervenções realizadas - deficientes, incompletas, embora válidas ou necessárias -, as iniciativas dos anos 1980 ainda precisam ser melhor estudadas. Julgá-las por seus resultados imediatos seria esquecer sua principal contribuição que foi a de fundamentar as ações que na sequência seriam tidas como corriqueiras, já assumidas de forma mais generalizada no trato das cidades. Tais iniciativas buscaram, de modo geral, alternativas econômicas, com as prefeituras empenhadas em programas de geração de renda; de abastecimento, com programas de redução de intermediadores; de criação de postos de trabalho, com a flexibilização de legislações de uso do solo para a implantação de iniciativas produtivas; dentre outros programas que até então não encontravam referências entre as demais experiências já consolidadas na tratativa urbana.

Essas eram iniciativas de prefeituras que recém haviam vivenciado uma década não apenas com uma economia de parcos resultados, mas também de crescimento demográfico acumulado, migração continuada, baixo nível de organização societária e poucas condições de resposta gerencial, além de baixo preparo de seu corpo técnico para enfrentar fenômenos que lhes eram emergentes, desconhecidos e surpreendentes pela grande escala.

No terreno econômico, os anos 80 ficaram conhecidos como "a década perdida". Mas esse foi um período em que presenciamos, também, o ascenso da luta pelo restabelecimento da democracia no país, que culminou com a promulgação, em outubro de 1988, da nova Constituição Federal. Esta haveria de influenciar profundamente vários aspectos da vida nacional, e até mesmo as políticas e o planejamento urbanos. Os anos 80 haviam sido marcados pela recessão. Entre 1981 e 1992 a taxa média de crescimento econômico caíra para apenas 1,5\%, enquanto o crescimento populacional atingia $1,9 \%$ ao ano. Isto significou uma redução do PIB per capita. Paralelamente, em meio a uma grave crise fiscal, esgotava-se o padrão anterior de intervenção do Estado e de financiamento das políticas públicas. (PANIZZI, 1999, p. 23).

A esta década perdida de 1980 segue-se a chamada década da exclusão dos anos 1990. A crença no setor privado como agente capaz de assumir compromissos prometidos e não cumpridos pelo Estado fez com que diversos países se lançassem a uma exacerbação liberal consubstanciada naquilo que ficou conhecido como o Consenso de Washington.

Por fim, parece imprescindível dizer que este processo se reforçou exemplarmente no plano do pensamento e da condução das políticas econômicas com o dogmatismo que se sintetiza a partir do final dos anos 1980 no chamado Consenso de Washington, no qual, com base nas novas regras do jogo do circuito financeiro internacional, e em especial das possibilidades de financiamento dos Estados, se impõe uma série de constrangimentos às economias periféricas a partir de um receituário de caráter neoliberal. (CUNHA \& SIMÕES, 2009, p. 4).

Assim, a década de 1990, aquela que se constitui nesse ensaio como o terceiro momento do modo de se entender a cidade por parte do poder público e das agências que lhe dão suporte financeiro, sem se permitir deixar de buscar responder aos compromissos dos momentos anteriores, acrescenta novos. Com isso, de modo vinculado ao que acontecia em nível global, com a criação de uma agenda novamente ampliada, o Brasil começa a substituir a Gestão Urbana por algo que se poderia definir como Gestão Ambiental Urbana. Iniciava-se pois a terceira desta curta retrospectiva da relação entre cidade brasileira e sua compreensão governamental. O discurso e a preocupação com o desenvolvimento social do momento anterior agora são compartilhados ou colocados em oposição aos novos e valorizados interesses ambientais. Dessa época surge a recorrente disputa 
entre a ocupação do solo urbano e o desenvolvimento de atividades produtivas versus o interesse conservacionista. Ficava clara, pois, uma divergência entre os pressupostos de uma ecologia urbana mais tradicional, que procurava, simples ou utopicamente, o equilíbrio e a adaptabilidade do morador urbano ao meio ambiente por meio de políticas públicas do poder local.

Prosseguindo na acumulação de complexidades para aquele que se propõe a pensar e agir sobre a cidade, na transição da segunda para a terceira fase, ao contrário da segunda para a primeira, percebe-se uma difusão de ideias e de práticas que, compreensivelmente, ora prioriza o social, ora o ambiental. A produção científica e o discurso político insistem na possível convivência e na possibilidade de satisfazer a ambos os interesses; a prática confirma uma dificuldade que nos obriga a priorizar um ou outro. Nesse momento, percebem-se coexistências ora possíveis, ora virtualmente inviáveis em nível da gestão.

A despeito desse possível sombreamento entre uma e outra prioridade, a emergência de questões ambientais junto à gestão de nossas cidades resulta de uma crise ostensiva quanto à qualidade $\mathrm{e}$ disponibilidade dos recursos naturais. Alguns autores, por exemplo, observavam a existência de um divisor temporal na questão urbana que é aquele marcado pelo fim do modelo desenvolvimentista, pela agudização das crises sociais e pela emergência do tema ambiental (PACHECO et al., 1992). $\mathrm{O}$ fato de a questão ambiental surgir como um fator importante para as prefeituras municipais em momento de agudização de crises, ou mesmo, como o é para muitos autores, delas decorrente, faz com que seja possível conectar problemas ambientais urbanos com infraestruturas e serviços públicos inadequados ou inexistentes. É dessa forma, aliás, que migrou-se, adaptada e adequadamente, de uma preocupação ambiental pensada para ambientes não antropizados para uma preocupação ambiental em espaços construídos e de alta densidade. Se, num primeiro momento, a preocupação com a devastação dos recursos naturais (devastação florestal, por exemplo) surge no meio urbano como uma preocupação tão somente com cortes de árvores e desejo de aumento de área verde, num segundo momento migra para uma defesa de serviços e infraestruturas urbanas que conciliem interesses estritamente ambientais (a não poluição dos rios, por exemplo) com a garantia do atendimento a necessidades urbanas (disponibilidade de água passível de ser tratada em volume suficiente para consumo atual e futuro e de maneira economicamente viável). Estávamos pois próximos da adoção do conceito ampliado de sustentabilidade em nossos espaços urbanos, porém ainda muito vinculados à antiga preocupação de ecologia urbana, hoje já reconhecida pelas suas restrições em conciliar uma agenda mais propriamente ambiental com a social e a econômica.

Se os anos 1990, ou a terceira fase de nossa forma de gerir as cidades brasileiras, se caracterizam pela valorização da questão ambiental, sugere-se também aqui que esses foram anos de sublimação do capital. As cidades não apenas assimilam o discurso ambiental mas - conjunção temática e temporal ainda a ser melhor estudada - são levadas a um esforço de empresariamento e concorrência de lugares a ser implementado pelo setor privado. No nível internacional, Harvey (1996) anunciava esse empresariamento segundo uma competividade que se organizava em quatro grandes eixos: a cidade competindo como centro produtivo (atraindo capital para seu território), como centro de consumo (buscando se constituir em polo turístico, por exemplo), como centro financeiro nacional ou global e como destino importante do capital estatal (atraindo sedes de agências e recursos governamentais). No nível nacional, a literatura científica identifica esse mesmo processo.

Assim, por exemplo, Vainer (2009, p. 76) afirma que

Se durante largo período o debate acerca da questão urbana remetia, entre outros, a temas como crescimento desordenado, reprodução da força de trabalho, equipamentos de consumo coletivo, movimentos sociais urbanos, racionalização do uso do solo, a nova questão urbana teria, agora, como nexo central a problemática da competitividade urbana.

Competitividade essa baseada nos princípios do planejamento empresarial e transformada, em âmbito urbano, em planejamento estratégico. Para Vainer (2009) a cidade se transforma assim em: 
cidade-mercadoria, cidade-empresa e cidade-pátria, revelando as novas determinações da questão urbana e o novo conteúdo do planejamento urbano, cujo resultado é a apropriação da cidade por interesses empresariais globalizados, sob tal lógica a cidade apresenta-se como uma mercadoria que deve ser vendida, o que se faz por meio da estratégia do marketing urbano.

Ainda sob forte influência do mercado - que a despeito da crítica, segue valorizado - e da perspectiva ambiental - que se renova com discursos e preocupações atualizadas, como aquele que agora se observa em relação às adversidades naturais, desastres e situações de emergência - os anos 2000 anunciam o quarto momento da gestão urbana brasileira. Todavia, muito menos na revisão do papel de um forte setor privado e muito mais na mudança no entendimento da questão ambiental que se pode verdadeiramente anunciar uma nova fase no trato da cidade brasileira. Na ostensiva dicotomia entre o conservar e o atender a demandas sociais de parcelas da população mais carente, conforme observado na década anterior, parece agora fazer sua opção pela segunda.

De fato, a partir da Constituição de 1988, com seus princípios norteadores e, de 2001, de forma mais específica, com a aprovação do Estatuto da Cidade, a gestão urbana brasileira assiste a uma série de ações que constituiriam o assim denominado quarto momento da retrospectiva aqui proposta. Esta nova gestão - que muito arriscadamente poderia ser denominada de Gestão Social seria agora caracterizada por uma forte tendência de descentralização administrativa, por uma maior participação da sociedade e por intervenções urbanas que buscam a renovação e revalorização de compartimentos das cidades brasileiras, fruto de uma postura dita inclusiva. Nos anos 2000, talvez pela primeira vez, o Brasil passa a contar com uma política urbana, a qual, ainda que sem um documento formalmente constituído, se apresentou na prática de forma bastante contundente . $\mathrm{O}$ melhor exemplo desta suposta política seriam os planos diretores municipais, agora, obrigatoriamente participativos. Desnecessário dizer que tal postura desejadamente participativa está sujeita a grandes críticas em termos qualitativos e mesmo em relação aos seus resultados concretos. Todavia, observou-se nesses anos um distinto esforço, apoiado pelo governo federal e pelos estados, em se planejar as cidades brasileiras, em discuti-las em processos democráticos e em entender suas áreas mais carentes. Do desejo à realidade e do proposto ao concretizado muitas lacunas restaram, muitos desapontamentos surgiram, sem dúvida. Na realidade, o fato de já contarmos em nossa história urbana recente com esforços similares e com resultados recorrentemente criticados, talvez justifique receios, como o apontado a seguir.

Muito se tem dito dos resultados positivos desses instrumentos contemporaneamente aplicados em termos de capacitação, ou seja, o processo tem sido educativo para se entender as cidades e para participar democraticamente das decisões governamentais. Todavia, mais uma vez esses são resultados pouco significativos para justificar a caracterização de uma nova fase na gestão urbana brasileira, mesmo porque são fenômenos já observados anteriormente, de forma dispersa nas fases anteriores. (ULTRAMARI \& REZENDE, 2006, p. 27)

Relativamente às fases/momentos aqui descritos, pode-se dizer que a gestão urbana brasileira adotou, em seu discurso oficial, um caminho onde se observaram, cumulativamente, a ampliação de suas responsabilidades, um maior compromisso com a população de menor renda e um triplo e difícil compromisso compartilhado entre demandas ambientais, sociais e restrições econômicas. A verdadeira adoção desse discurso na prática e a abrangência desse pragmatismo ideológico, deve-se ter em mente, merecem debates ampliados: seja pela timidez de seus resultados, seja pela verdadeira intenção de sua prática, seja, ainda, pela durabilidade de sua intenção.

A forma como os momentos descritos se distinguem guarda a característica de um lento processo e, muitas das vezes, com a repetição de práticas falhadas. Tal situação, sem ignorar avanços positivos, alerta para o fato de que talvez estejamos distantes de romper velhas estruturas há muito estabelecidas ou mesmo para o fato de que, olhadas em uma temporalidade maior, tais fases possam ser constitutivas de um verdadeiro e único grande período, no sentido daquilo que afirma Thomas 
Khun (1996), para quem é importante que, para a constituição de mudanças profundas, paradigmáticas, essas ocorram aos saltos e não de forma contínua. Certamente, se analisadas as quatro fases/momentos do ponto de vista dos resultados que seus discursos apresentaram, elas perdem a singularidade e justificam desencantamentos. Se analisadas do ponto de vista de uma possível continuidade, e minimizado o fato de que elas cobrem um período de quarenta anos, há razões para uma postura mais otimista. De fato, o que se observa neste quarto momento da gestão urbana brasileira - a Gestão Urbana Social - é uma crescente complexidade imposta pela realidade, mas que, de fato, é reconhecida pelo gestor, refletindo uma das facetas atuais da cidade brasileira e do compromisso assumido pelos agentes que a gerem. Vale claro, a lembrança da concreta distância entre discurso e prática, entre desejo e realidade; entretanto, cabe também lembrar que, do ponto de vista da práxis do planejamento e da gestão, parece não haver dúvidas que a complexidade imposta e adotada garantiu posturas de gerência com maiores chances de acerto. Num possível e necessário ceticismo para qualificar o otimismo aqui defendido, poder-se-ia dizer que estamos então distantes de um árduo trabalho de Sísifo, sofrido, interminável e sem resultados, mas, ao mesmo tempo, próximos de boas mudanças sofridamente conquistadas.

Na sucessão dos quatro momentos aqui discutidos - Ação Administrativa, Gestão Urbana, Gestão Ambiental Urbana e Gestão Urbana Social - o que se observa é, também, uma alternância de instrumentos de gestão e entendimentos da cidade ao longo das décadas, ora valorizando ora relegando prioridades e agentes executores do seu processo de construção. Ao final da acumulação de tais fases, estariam estabelecidos como parâmetros de referência a participação de um maior número de agentes numa gestão que se quer urbana, ambiental e social. Cumulativamente, fazem parte da agenda do gestor urbano-ambiental-social, a priorização de áreas mais carentes da cidade, a valorização da questão ambiental, a consideração do capital social disponível nessas comunidades e, aquilo que pode parecer paradoxal por parte de princípios universais, a defesa de soluções alternativas, dentre outros.

A síntese dessas quatro fases/momentos da gestão urbana no Brasil não é, sem dúvida, tarefa fácil. O que parece certo é a existência de uma adição de complexidades e de responsabilidades que ao longo do tempo se impõem ao gestor urbano e àqueles que ensaiam pesquisá-la e entendê-la. Se, por um lado, muitos problemas restam sem solução; por outro, eles se incrementaram em número e em complexidade. De uma agora simples preocupação em administrar a cidade, buscando a oferta de infraestrutura e serviços básicos, passou-se para uma compreensão mais abrangente, ensaiando-se alternativas de desenvolvimento ou mesmo de sobrevivência. Prosseguindo na construção desse processo cumulativo, agregaram-se as preocupações ambientais por meio das quais se assumiram desejos de uma cidade mais justa.

\section{MUDANÇAS HÁ MUITO DESEJADAS}

O estabelecimento das fases pretéritas de um curto processo da gestão urbana no Brasil não facilmente explica o presente ou clareia a investigação do futuro. Todavia, a hipótese que aqui se toma como possível é que há, neste processo, um forte caráter cumulativo, menos de grandes transformações, mas muito mais de assimilação de responsabilidades, de competências e complexidades. Tal acumulação facilita o deslumbre de como a realidade pode se apresentar e, mais facilmente, de como o presente se constitui.

Neste item são priorizados quatro fenômenos que se podem julgar importantes para a caracterização do atual momento urbano vivenciado no Brasil. Esses fenômenos resultam da combinação de uma acumulação de problemas vivenciados e de uma busca por soluções empreendidas observadas em cada um dos momentos anteriormente tratados e das posturas governamentais e societárias que o caracterizaram. Outros pontos poderiam ser agregados, sem dúvida; os que aqui se apresentam, mais uma vez, o são de forma tão somente contributiva a um debate maior, constituindo, intencionalmente, possibilidades de análise da realidade urbana brasileira. 


\section{Reduções das taxas de crescimento demográfico}

A questão demográfica conta com uma longa tradição de estudo no período aqui discutido, talvez justamente pela própria importância da forte dinâmica de migração rural-urbana que muito impactou o processo de urbanização recente. Para além de uma justificativa que pode ser encontrada na própria escala da questão, alguns autores ainda indicam como explicação dessa tradição no debate demográfico o papel das agências internacionais com seus ideários presentes em programas de fomento e desenvolvimento por elas financiados.

O notável crescimento da área de demografia no país foi impulsionado, em parte, pela preocupação internacional com o crescimento populacional e pelos recursos colocados à nossa disposição. [...] Direta ou indiretamente, isto acabou beneficiando os pesquisadores e as diversas instituições de ensino e pesquisa agora existentes no país. (MARTINE, 2005, p. 257).

Nesta influência de agências internacionais de fomento e financiamento em estudos científicos e programas urbanos diversos, observa-se uma oposição entre as que apoiam o planejamento familiar e a redução da fecundidade e aquelas que estimulam estratégias mais estruturais, contribuindo para uma verdadeira postura crítica no debate demográfico nacional. Para aquilo que interessa ao debate sobre o urbano neste artigo, ressalta-se a convivência entre uma postura neomalthusiana que se preocupa com os números de crescimento que erroneamente parecem ser socialmente homogêneos e uma outra que não aceita desvincular a discussão desse mesmo crescimento da forma socialmente díspare com que as cidades crescem. Da perspectiva social, nossas cidades persistem em apresentar indicadores de fortes disparidades na forma de ocupação do solo, no modo de absorverem heterogeneamente os impactos negativos e positivos de um processo econômico com reduzida sustentabilidade ambiental, e na maneira com que serviços e infraestruturas básicas são apropriados. Do ponto de vista da administração das cidades, observa-se que a queda nas taxas de crescimento demográfico têm oportunizado um cenário mais ampliado de ações da parte dos poderes locais e maiores chances de se efetivar suas propostas de planejamento urbano.

A apropriação dessas oportunidades e facilidades é variável, revelando uma miríade de situações diferenciadas entre os municípios brasileiros. Todavia, de modo geral, o rápido processo de queda nas taxas demográficas, em princípio, significou uma desaceleração no crescimento das demandas sociais não atendidas pelo poder público. Adicionalmente, tal fato implicou previsibilidade incremental no exercício do planejamento, pois se reconhece que cenários de reduzida dinâmica demográfica ampliam as chances de acerto dos exercícios de previsibilidade.

Igualmente importante é a velocidade com que esse processo de redução do crescimento demográfico se deu no território brasileiro e sobretudo em suas áreas urbanas: não apenas as quedas foram significativas, mas igualmente o lapso de tempo dessas mudanças foi curto.

O exame da dinâmica demográfica brasileira das últimas décadas revela importantes transformações, com fortes impactos nas demandas por serviços públicos, [...]. A tendência do processo de queda nos níveis de fecundidade no país tem surpreendido pela sua velocidade e pelo seu caráter generalizado. Quem acompanhou o lento declínio na fecundidade brasileira, [...] , de certo modo se surpreende com o fato de o país ter alcançado, de forma tão rápida, valores tão próximos aos dos países desenvolvidos, cujo processo de queda na fecundidade se deu em um período de tempo muito maior. (CERQUEIRA \& GIVISIEZ, 2004, p. 1).

Certamente, esse processo não ocorre sem receios de outras implicações, como o envelhecimento da população e o surgimento de demandas ainda mais complexas ao gestor urbano. Entretanto, a realidade que ora se apresenta é significativamente diferenciada daquela dos anos de $1970 \mathrm{com}$ seu processo de urbanização, metropolização e concentração demográfica. 
Desse modo, de uma taxa de urbanização de $56 \%$ da população em 1970 , o país alcançou $81 \%$ em 2000 e $84 \%$ em 2010, o breve período de tempo em que tal transformação ocorreu resultou na exacerbação de problemas urbanos de toda ordem e na dualidade anteriormente referida, além de significativas mudanças no âmbito da rede urbana nacional, promovendo a emergência das cidades intermediárias e seu processo de atração populacional, além da maior dispersão das cidades pelo território com o surgimento de cidades no interior do país, numa explícita estratégia de interiorização da rede urbana.

Persistem ainda um déficit de demandas quantitativamente não atendidas, porém o processo cumulativo que até então se observava arrefeceu, o que permite o direcionamento de esforços e recursos para a diminuição do passivo. Ainda que os sinais sejam tímidos em termos de resultados dessas ações, há certamente um cenário de maiores potenciais para que se possa agir.

\section{Maior disponibilidade de informações para se planejar}

O forte crescimento urbano dos anos de 1970 ocorreu em meio a um cenário administrativo de ostensiva precariedade em termos de provimento de infraestruturas e serviços e também de baixo domínio de informação sobre a nova sociedade urbana que se constituía, bem como sobre sua distribuição espacial e territorial. Tais limitações foram reconhecidas em programas de financiamento, sobretudo aqueles com recursos internacionais, constituindo mesmo uma das características mais marcantes desses instrumentos nas décadas de urbanização acelerada. Se, num primeiro momento fato que pode ser reconhecido como um dos elementos norteadores dos anos de 1970 -, as agências internacionais de financiamento preocupavam-se em implementar aquilo que nomeavam de "obras básicas", já para o final dessa década e também nos anos de 1980 e 1990, buscou-se o chamado desenvolvimento institucional, mas agora segundo renovadas diretrizes neoliberais.

O interesse do Banco Mundial pelo governo municipal data de meados da década de 70, [...] ao avaliarem os programas para combate do déficit habitacional [...] chegaram à conclusão que estavam diante de um fracasso. Naquele momento dois projetos se destacavam: site and service e slum upgrading. [...] Frente a essa situação, buscaram alternativas, [...] Reconheciam, no entanto, que o poder público local, em sua grande maioria, não era qualificado para gerir programas deste tipo ou de desenvolvimento urbano. Assim, verifica-se um redirecionamento nos fundamentos das operações urbanas do Banco Mundial, que passou a dar maior ênfase à capacitação técnica das prefeituras nos processos de gestão e de planejamento urbanos. (RIBEIRO FILHO, SILVA e ANDRADE, 2010, p. 3).

Deste período destacam-se os esforços iniciais de um serviço de informações que iria se consolidar muito mais tarde e ainda com limitações para a maioria dos municípios brasileiros. Um dos exemplos desses esforços em capacitar os municípios brasileiros para o exercício do planejamento se consubstanciou no apoio à realização de seus Planos Diretores no final dos anos de 1970. Tais Planos, do mesmo modo como aconteceria novamente nos anos $2000 \mathrm{com}$ os chamados Planos Diretores Participativos, a despeito de reduzida aderência com a realidade urbana e com mudanças necessárias, contribuíram para a criação de um acervo de informações sobre o território urbano a ser trabalhado. De lá para cá, ampliaram-se não apenas o acervo mas igualmente também a interatividade e a multifuncionalidade de informações espacializadas, por exemplo. Detectaram-se poucos resultados decorrentes desses Planos, mas certamente constituíram uma primeira aproximação mais abrangente do fenômeno urbano em nossas cidades. Desse modo, a despeito do reiterado fracasso do grande esforço de realização dos Planos Diretores nesta década, recorrentemente denominados de planos de gaveta, assistiu-se ao início de um longo processo de desenvolvimento institucional, capacitação funcional das prefeituras e disponibilização de informações. Criados sob uma visão tecnicista - conforme avaliado na discussão sobre a fase da Ação Administrativa dos anos 1970 tais planos, ironicamente, constituíram em recurso pedagógico no entendimento posterior que se buscaria da cidade brasileira. De fato, os chamados planos participativos originados dos princípios do Estatuto da Cidade buscam precisamente o oposto a esse tecnicismo fracassado. 
Essa mesma postura tecnicista, característica do período militar que se vivia no país, influenciou também outros fatores da gestão das cidades daquela época; igualmente, tal postura recorrentemente criticada serviu de anátema aos novos instrumentos de gestão que mais recentemente procurar-se-ia adotar. Se, por exemplo, a definição das regiões metropolitanas pela Lei Complementar nº 14/1973 seguia interesses políticos de um governo federal altamente centralizador, a revisão dessa prática no período pós-Constituição de 1988 buscou seu reverso junto à autonomia de governos estaduais e mesmo de iniciativas locais.

Assim, de um processo centralizado e coordenado pelo governo federal, chega-se, no período recente (pós anos de 1990), numa realidade completamente oposta, qual seja, aquela onde não há qualquer coordenação nacional e tampouco definições abrangentes acerca da compreensão do sentido das regiões metropolitanas no Brasil, ficando a critério de cada Estado da federação sua definição e implementação.

De fato, mesmo o processo de implantação das estruturas de gestão metropolitana dos anos 1970 se faziam, também, segundo o intuito da capacitação dos municípios. Oportunisticamente, mais de uma vez, a centralização das decisões era justificada pela declarada "incapacidade técnica" de os municípios gerirem seus próprios territórios. Para exemplificar essa prática, tem-se o texto da Lei Federal n ${ }^{\circ}$ 6766/1979, na qual os municípios metropolitanos submetem o parcelamento de seu solo urbano a um processo de anuência do órgão estadual metropolitano. Comparativamente, demonstrando uma alteração no nível de centralização até então adotado, tem-se o texto da Lei Federal $n^{\circ}$ 9785/99 que altera o texto de 1979 e flexibiliza a exigência da outorga.

Art. 13 - Caberão aos Estados o exame e a anuência prévia para a aprovação pelos Municípios, de loteamentos e desmembramentos nas seguintes condições:

I - Quando localizados em áreas de interesse especial, tais como as de proteção aos mananciais ou ao patrimônio cultural, histórico, paisagístico e arqueológico, assim definidas por legislação estadual ou federal;

II - Quando o loteamento ou desmembramento localizar-se em área limítrofe do município, ou que pertença a mais de um município, nas regiões metropolitanas ou em aglomerações urbanas, definidas em lei estadual ou federal;

III - Quando o loteamento abranger área superior a 1.000.000 m2 (um milhão de metros quadrados)

Parágrafo único. No caso de loteamento ou desmembramento localizado em área de município integrante da região metropolitana, o exame e a anuência prévia à aprovação do projeto caberão à autoridade metropolitana. (LEI FEDERAL No 6766/1979).

Art. 13 - Aos Estados caberá disciplinar a aprovação pelos Municípios de loteamentos e desmembramentos nas seguintes condições: repete anterior (LEI FEDERAL No 9785/99).

Evidentemente, se observada do ponto de vista das instituições internacionais influentes na formatação de nossas políticas urbanas, essa mudança de postura - de uma Ação Administrativa, fundamentada em intervenções, para uma gestão preocupada com o planejamento e capacitação institucional - representou um forte desejo de se reduzir o papel do Estado, agora mais alinhado aos interesses neoliberais.

O Banco Mundial, que até os anos de 1970 se dedicava a emprestar principalmente para grandes projetos estruturadores, modifica sua forma de operar. ... passa a realizar empréstimos de ajustes estruturais e setoriais. Caracteriza-se a partir daí forte interferência da instituição nos assuntos internos dos países. Estes novos tipos de empréstimos tinham como objetivo ajustar as contas públicas, estabelecendo 
mecanismos para que os países alcançassem superávit primário para pagamento das dívidas externas. Os empréstimos passaram a ser destinados prioritariamente para temas que o Banco Mundial denominava de "reforma do Estado", "modernização administrativa", "fortalecimento da gestão", "construção de capacitação", implantação de "governance" etc. (RIBEIRO FILHO, SILVA e ANDRADE, 2010, p. 7).

Esta mudança de postura na forma de as instâncias do governo brasileiro atuar nas cidades significou, posteriormente, uma assimilação de práticas empresariais para o nível da gestão pública. Mais uma vez, confirma-se o perfil processual da descrição aqui feita: já se preparava a defesa e a adoção de modelos denominados estratégicos de uma cidade em processo de empresariamento. Desta maneira, acreditava-se preparar a cidade para um ambiente de competitividade em nível global e para que se procedesse a aproximações parceiras entre o setor público e o privado. A cidade que até então se apresentava com indicadores baixos para justificar um eventual pedido de recursos ao poder público é então incentivada a elaborar programas de marketing para concorrer no mundo privado. As críticas a esse modelo, esperada e justificadamente (conforme o futuro confirmaria) não foram poucas, caracterizando mesmo grande parte da produção científica urbana brasileira. Tais críticas se fizeram a partir do temor de uma cidade que buscava no mercado as soluções de mazelas que o Estado não fora capaz de resolver, um temor que se justificava pela possível implantação de cidades com pensamentos únicos. Sanchez (2001, p. 98) ao proceder uma síntese dessas críticas ao resenhar o livro A cidade do Pensamento Único (2001), afirma:

O modelo generalizou-se, virou receita difundida mundo afora. A cidade, transformada em mercadoria, é posta em circulação e, mediante imagens que operam a serviço dessa visão mercadológica, são descortinados seus atrativos comerciais, turísticos e culturais, na busca de atração de investimentos. Para dentro da cidade, a mercadotecnia urbana gera uma visão de cidadania que assalta, principalmente, os próprios cidadãos.

A crítica generalizada a esse modelo, compartilhada no presente texto, ainda permanece para ser estudada em termos de sua contribuição. Se ruim para a cidade, e isso é o que importa, a adoção desse modelo pode ter agregado práticas de maior eficiência administrativa à gestão. $\mathrm{O}$ resultado ruim generalizado não pode justificar o bom reduzido, sem dúvida; porém, é possível identificar uma maior preocupação com a prestação de serviços públicos, bem como com a oferta e manutenção de infraestruturas. A assimilação de algumas práticas de mercado pode ter criado uma práxis de um maior comprometimento na relação poder municipal e morador urbano. Nesse sentido acredita-se que a maior disponibilização de informações não apenas contribui para a ação do planejamento mas também tem apoiado a vigilância popular sobre o provedor desses mesmos serviços e infraestruturas.

\section{Maior participação comunitária}

A participação popular na construção de uma política urbana nacional talvez possa ser considerada o objetivo mais longamente perseguido na história recente da gestão de nossas cidades. Tal objetivo constituiu um processo, ora com avanços, ora com retrocessos, mas sem dúvida, ampliando-se ao longo do tempo, aí incluindo uma eventual adição de qualidade no uso das ferramentas participativas.

Tradicionalmente, a participação popular como elemento importante no processo de gestão urbana brasileira é referenciada na Constituição Federal de 1988 e posteriormente no Estatuto da Cidade de 2001; a primeira estabelecendo princípios e o segundo definindo mecanismos mais concretos. Enquanto a Constituição expressa um novo conceito de participação popular, a partir da universalização dos direitos sociais, o Estatuto, sobretudo por meio do Plano Diretor Participativo, agora entendido como "instrumento básico da política de desenvolvimento e expansão urbana" (Art. $n^{\circ} 40$ ), impõe uma prática que até então era aleatória no cotidiano do gestor.

Todavia, para os propósitos desse texto, essa participação pode ser encontrada nos anos 1970, quando dos fortes sinais de fracasso das políticas desenvolvimentistas do governo brasileiro e, 
conforme lembrado por Castells (1983), das chamadas "contradições urbanas". De tais contradições surgiram, esperadamente, os movimentos sociais que responderiam a imposições à sua força de trabalho. Segundo Portela (2005, p. 32) esse fenômeno contribui para a "criação de um processo de politização do cotidiano, tendo em vista a ação contraditória do Estado". Isso significou, ainda que com grandes limitações, um entendimento mais abrangente da questão urbana, e portanto de sua gestão. Esta deixaria, intencionalmente, de ser integralmente tecnicista e prioritariamente físico-territorial. A partir de então a gestão urbana passaria a ser multidisciplinar, envolvendo especialidades de diversas áreas que não apenas a arquitetura e a engenharia; do mesmo modo, essa gestão passaria a ser mais democrática, já envolvendo outros agentes sociais que não apenas aqueles do corpo técnico dos governos. Assim se constituía o que seria denominado entre nós de planejamento urbano, afastando-se do urbanismo praticado até então. De fato, como visto anteriormente, a Ação Administrativa dos anos 1970, crente na exclusiva capacidade do tecnicismo, dá lugar a uma Gestão Urbana dos anos 1980, a qual serviria como referência para os ganhos da Gestão Urbana Social duas décadas a seguir. Começaria aí uma longa fase de uma gestão urbana habituada a poucos recursos para intervenção e agora mais dedicada ao pensar a cidade, ao elaborar seu planejamento (ULTRAMARI, 2009, p. 35). Desta época, anos 1980, restou um aprendizado sobre o gerir a cidade, a planejá-la e a dividir a gestão com um maior número de agentes sociais; um processo que, conforme dito anteriormente, iria se oficializar, depois de um longo período de luta pela reforma urbana, na Constituição de 1988 e no Estatuto da Cidade.

Atualmente, a despeito de grandes receios sobre a verdadeira transformação trazida por esses instrumentos, é certa a oficialização de práticas participativas implementadas, por exemplo, em conselhos, diagnósticos participativos, conferências municipais diversas e audiências públicas. Avaliar os resultados desses instrumentos ainda é difícil. Do mesmo modo, a prática participativa ainda reflete problemas qualitativos e uma sociedade carente que gestiona para a garantia daquilo que lhe é básico. Com isso, permanecem válidas as críticas de que a atual participação constitui um exercício de "ações de fala" e mesmo de "atuação simbólica",

Pois, no decorrer do processo de planejamento, denota-se uma desigualdade profunda entre a perícia discursiva dos planejadores com suas concepções, lógicas e modelos abstratos e as ricas vivências dos "participantes" que procuram fazer valer suas experiências concretas no processo do planejamento que se esquivam de uma fácil verbalização e representação dominantes. (RANDOLPH, 2007).

As críticas são ainda mais veementes se dirigidas especificamente ao grande esforço realizado para a elaboração dos Planos Diretores Participativos nesses anos 2000. Esses Planos são criticados pela possível postergação estratégica da implementação de mudanças há muito desejadas, "mudando-se pouco para nada mudar" (ULTRAMARI, FIRMINO e SILVA, 2011, p. 5), ou então pela sua intrínseca limitação transformativa. Neste caso, ressalta-se a conhecida "ilusão do Plano Diretor Participativo" relatada por Flavio Villaça (2005), segundo a qual o desejo de uma gestão mais participativa ocorre em meio a uma inerente dificuldade de se conciliar interesses entre grupos e classes sociais diversas (com poderes e interesses políticos e econômicos muito diferentes). Mais que isso, Villaça alerta para o fato de que participação exige um mínimo de igualdade social, pressuposto ainda buscado em nossa realidade urbana.

Frente a esses receios, ainda assim, arrisca-se dizer que há grandes avanços: a participação hoje existe e deve seguir um caminho de qualificação, seja por meio do aprendizado na prática, seja por conta dos sinais de uma redução nas disparidades sociais e apropriação daquilo obtido a partir da vida nas cidades por uma parcela maior da população. Relativamente aos Planos Diretores Participativos dos anos 2000, trabalhos de investigação posteriores ao momento atual vivenciado poderão confirmar essa hipótese; se comparados com o resultado trazido pelos Planos de Gaveta dos anos 1970, sobra, minimamente um conhecimento acumulado sobre o complexo processo urbano e uma gestão participativa com difícil retrocesso. 
Poucas vezes o ideário parece ter se constituído em realidade. Este talvez seja o caso das políticas e ações prioritariamente sociais que se têm observado nos últimos anos, sobretudo a partir da consolidação dos princípios estabelecidos pela Constituição de 1988. Há muito entendida como objetivo principal de uma eventual reforma urbana, as políticas inclusivas começam a ser praticadas primeiramente pela luta urbana, com alguns ganhos, posteriormente por um discurso oficial quando pressionado por esses mesmos movimentos e mais recentemente, já como fatos da década de 2000, assumidos em projetos diversos. Para a década que se apresenta a seguir não há sinais de arrefecimento, ao contrário, devem prosseguir as prioridades, por exemplo, de reurbanizações de assentamentos precários e mesmo de um acirramento da polêmica entre o interesse social e o ambiental. Essa polêmica, ao mesmo tempo que obriga a uma atualização do discurso ambiental e social, sugerindo inclusive uma revisão do conceito de sustentabilidade que acreditava na indiscutível compatibilidade desses interesses, reitera a valorização assumida pelas parcelas da cidade onde a renda é mais baixa e as demandas básicas estão longe de ser atendidas.

Sem dúvida, tais sinais de valorização da questão social e assim das parcelas mais necessitadas da população, resulta de um longo e pouco linear processo de lutas.

Para Ermínia Maricato (1997), por exemplo, essa luta inicia nos agora distantes anos 1970, por meio de setores da Igreja Católica em apoio a trabalhadores do campo. Esse mesmo início pode ainda ser localizado nos anos 1960, quando, o Instituto de Arquitetos apresenta ao Congresso uma proposta intitulada de Reforma Urbana (SAULE JR \& UZZO, 2009). A despeito de alguns poucos avanços, resultado de iniciativas dos anos 1970 e 1980, esse esforço se consolidaria de modo legal apenas em 2001, com o Estatuto da Cidade, reiterando e avançando no entendimento da função social da propriedade anunciada pela Constituição Federal de 1988.

A acreditar que os Planos Diretores Participativos dos anos 2000 de alguma forma impliquem em mudanças na realidade urbana brasileira, é importante observar que dentre seus princípios mais recorrentes está a proposição de soluções fundiárias para as chamadas áreas carentes, em sua maioria denominadas de zonas especiais de interesse social. A simples constante observação dessa realidade, quase inexistente em planos de décadas anteriores, significa a publicização de um interesse social, de um compromisso estabelecido.

\section{CONSIDERAÇÕES FINAIS}

A rápida revisão sobre a gestão urbana brasileira nas últimas quatro décadas e o curto ensaio sobre possíveis tendências que delas podem ser elaboradas contém, propositadamente, um perfil de otimismo. A intenção deliberada para se manter o otimismo do começo ao fim deste artigo não foi desprovida de esforço; optou-se por, em meio a um cenário de crises cumulativas, identificar aquilo que pode ter sido positivo. Reconhece-se aqui a persistência de grandes dificuldades administrativas, de sérias desigualdades sociais, do anúncio de incrementos dos problemas ambientais e a previsibilidade de acúmulo de adversidades ambientais.

A questão de a história explicar o presente e ajudar a corrigir erros futuros é contenciosa; porém, a gestão urbana brasileira já conta com uma longa e rica retrospectiva e com prática sobre uma cidade de modelo ainda válido. A permanência desse modelo, complexo, desigual, dinâmico e algumas vezes fracassado, deve servir como experiência adquirida.

Este artigo referenciou-se fundamentalmente numa prática profissional/pessoal entendendo-as como indissociáveis; contudo, outras perspectivas existem. A segunda parte desse texto poderia ter adotado a análise apoiada em indicadores temporalmente seriados, diversos e usuais na discussão do urbano; neste caso, o enfoque dificilmente, arrisca-se dizer, deixaria de ser igualmente otimista.

Com isso, conclui-se que, para o caso dessa discussão, o passado pode, sim, explicar o presente e anunciar o futuro. No prazo aqui discutido, iniciado na década de 1970 e finalizado na de 2000 , 
observaram-se complexidades crescentes no objeto em questão, a cidade e a sua gestão. Porém, igualmente, observaram-se incrementos na capacidade de geri-la. Tem-se, atualmente, um cenário demográfico mais consolidado, um corpo técnico nas prefeituras mais preparado, uma organização civil que apresenta transformações positivas de participação, um acervo de informações urbanas que garante a construção técnica de um processo de planejamento melhor referenciado na realidade, uma estrutura institucional há muito requerida e um aparato legal minucioso. Tais aspectos se qualificam como positivos não apenas pela perspectiva do momento atual, o que indicaria um simples juízo de valor, mas sobretudo por resultarem de um longo processo cumulativo e, mais importante, desejado. Já se sabe que o bom não é para sempre, mas a análise proposta e da forma como foi realizada pode indicar que o mal tampouco o é.

\section{REFERÊNCIA BIBLIOGRÁFICA}

ARANTES, Otília Beatriz Fiori; VAINER, Carlos; MARICATO, Ermínia. A cidade do pensamento único. Desmanchando consensos. Coleção Zero à esquerda, Petrópolis: Vozes, 2000.

BODNAR, J., 2007-08-11 "Dual Cities, Globalization and Uneven Development" Paper presented at the annual meeting of the American Sociological Association, TBA, New York, New York City Online. Disponível em http://www.allacademic.com/meta/p184503_index.htmlp. Acesso em 02 de janeiro de 2011. BRASIL. Lei Federal nº 6766 de 19 de dezembro de 1979.

BRASIL. Lei Federal no 9785, de 29 de janeiro de 1999.

CERQUEIRA, Cézar Augusto e GIVISIEZ, Gustavo Henrique Naves, Conceitos básicos em Demografia e dinâmica demográfica brasileira. In: RIOS-NETO, Eduardo Luiz G. e RIANI, Juliana de Lucena Ruas (Org.), Introdução à demografia da educação. Associação Brasileira de Estudos Populacionais, ABEP. Campinas, 2004.

COMEC (Coordenação da Região Metropolitana de Curitiba). Urbano e regional: o contexto pós-constitucional em debate. Curitiba, 1991.

CUNHA, A.M. e SIMOES, R.F. Política Regional e Avaliação: desafios para uma leitura crítica do caso brasileiro. In: Encontro Nacional da Associação Brasileira de Estudos Regionais e Urbanos - ENABER, 7 , 2009, São Paulo. Anais... São Paulo: s.n., 2009.

FERNANDES, Sérgio Araújo. Agenda internacional de gestão urbana e o caso do programa Ribeira Azul. Cadernos Gestão Pública e Cidadania. Vol. 9, nº 39. São Paulo: Fundação Getúlio Vargas, junho 2004.

HARVEY, David. Do Gerenciamento ao Empresariamento Urbano: a transformação da administração urbana no capitalismo tardio. Revista Espaço \& Debates, nº 39, 1996. p. 48-64.

KUHN, Thomas. The structure of scientific revolutions. Chicago: University of Chicago Press, 1996.

LEME, Maria Cristina da Silva. A formação do pensamento urbanístico no Brasil: 1895-1965. In: LEME, Maria Cristina da Silva; FERNANDES, Ana; GOMES, Marco Aurelio Filgueiras (orgs.) Urbanismo no Brasil 1895-1965. São Paulo: Studio Nobel/FAU USP/FUPAM, 1999.

MARICATO, E. Reforma Urbana: Limites e Possiblidades. Uma Trajetória Incompleta. In: RIBEIRO, Luiz César de Queiroz e SANTOS JUNIOR, Orlando Alves dos (Org.). Globalização, Fragmentação e Reforma Urbana. Rio de Janeiro: Civilização Brasileira. 1997, p. 309-325.

MARTINE, George. O papel dos organismos internacionais na evolução dos estudos populacionais no Brasil: notas preliminares. Revista Brasileira de Estudos de População. Vol. 22, nº 2, São Paulo July/Dec. 2005. PACHECO, Regina Silva et al. Atores e conflitos em questões ambientais urbanas. Espaço \& Debates, n. 35. São Paulo, 1992. p. 46-51.

PANIZZI, Wrana Maria. ANPUR: A Consolidação de uma Proposta, 1993-1995. Revista Brasileira de Estudos Urbanos e Regionais, n. 1, maio de 1999.

RANDOLPH, R. Do planejamento colaborativo ao planejamento "subversivo": reflexões sobre limitações e potencialidades de planos diretores no Brasil. Scripta Nova. [Em línea]. Barcelona: Universidad de Barcelona, 1 de agosto de 2007, vol. XI, no 245 (17). <http://www.ub.es/geocrit/sn/sn-24517.htm >. [21 de febrero de 2008]. 
RIBEIRO FILHO, Geraldo Browne. O Banco Mundial e a difusão de modelos de planejamento urbano e de gestão urbana para as cidades: o caso do PRODUR, BA. Encontro Nacional da ANPUR. Belém, 2009. Anais... Belém: s.n., 2009.

RIBEIRO FILHO, G. B.; SILVA, V. A.; BARBOSA, G. Z.; e ANDRADE, S. B.. Planejamento e Gestão Market Friendly em Cidades Brasileiras: as Operações Urbanas do Banco Mundial a partir dos anos de 1980. Pluris, $4^{\circ}$ Congresso Luso-brasileiro para o planejamento urbano regional integrado sustentável. Faro: Anais ... 2010.

SÁNCHEZ, Fernanda. A Cidade do Pensamento Único - Desmanchando Consensos, Otília Arantes, Carlos Vainer e Ermínia Maricato Petrópolis, Editora Vozes, 2000. Resenha. Revista Brasileira Estudos Urbanos e Regionais, $\mathrm{n}^{\mathrm{o}}$ 4, 2001. Disponível em http://www.anpur.org.br/revistas/Anpur_v4.pdf, acesso em 20 de outubro de 2011.

SANTOS, M. e SILVEIRA, M. L. O Brasil: território e sociedade no início do século XXI. Rio de Janeiro/ São Paulo: Ed. Record, 2002.

SAULE JR. N. \& SAULE JR \& UZZO, K. A trajetória da Reforma Urbana no Brasil. Banco de textos do Dialogues, Propositions, Histoires (DPH), 2009. Disponível em http://base.d-p-h.info/pt/fiches/dph/fiche-dph-8583.html Acesso em 15 de out., 2011.

UN-Habitat, UNESCO, MOST. Organizado por Brown, Alison e Kristiansen, Annali. Urban Policies and the Right to the City Rights, responsibilities and citizenship. Disponível em http://unesdoc.unesco.org/ images/0017/001780/178090e.pdf . Acesso em 06 de fevereiro de 2012.

ULTRAMARI, C. SIGNIFICADOS DO URBANISMO. PÓS - Revista do Programa de Pós-Graduação em Arquitetura e Urbanismo da FAUUSP, v.1 (1990- ), Semestral, v. 16, n. 25, jun. 2009

ULTRAMARI, C.; FIRMINO, R.; SILVA, S. F.P. Uma abordagem bibliométrica do estudo do Planejamento Urbano no Brasil nas décadas de 1990 e 2000. XIV Encontro Nacional da ANPUR. Maio de 2011, Anais

... Rio de Janeiro

ULTRAMARI, C. e REZENDE, D. Mudanças e Continuidades na Gestão Urbana Brasileira. Revista Paranaense de Desenvolvimento, Curitiba, n.111, jul./dez. 2006. p.19-28.

VAINER, Carlos. Pátria, empresa e mercadoria: a estratégia discursiva do Planejamento Estratégico Urbano. In: ARANTES, Otília Beatriz Fiori; VAINER, Carlos; MARICATO, Ermínia. A cidade do pensamento único. Desmanchando consensos. Coleção Zero à esquerda, Petrópolis: Vozes, $5^{\mathrm{a}}$ edição, 2009, p. 75-103. VILLAÇA, Flávio. Uma contribuição para a história do planejamento urbano no Brasil. In: DEÁK, Csaba; SCHIFFER, Sueli Ramos (org.) O processo de urbanização no Brasil. São Paulo: EdUSP, 1999. p. 169 - 243. VILLAÇA, F. As ilusões do Plano Diretor. São Paulo, agosto de 2005; disponível em http://www.planosdiretores.com.br/downloads/ilusaopd.pdf.

Trabalho enviado em fevereiro de 2012

Trabalho aceito em março de 2012 